\title{
A relevância da educação em ciências: posicionamentos de estudantes brasileiros de crenças cristãs acerca da teoria da evolução humana
}

\author{
The relevance of science education: positions of Brazilian students of Christian beliefs about the \\ theory of human evolution
}

\author{
Helenadja Santos Mota* \\ Nelio Bizzo ${ }^{* *}$ \\ Yzila Liziane Farias Maia de Araujo ${ }^{* * *}$
}

\section{Resumo}

A relevância do ensino da evolução biológica se alicerça na centralidade do tema que é considerado preponderante para a construção dos conhecimentos biológicos. Apesar do caráter fulcral, a evolução biológica é bastante controversa como temática nas aulas de ciências, fazendo com que muitos professores se esquivem de ensiná-la. Diante das dificuldades inerentes ao processo de ensino e aprendizagem da teoria evolutiva, especialmente da evolução humana, o presente trabalho busca identificar o grau de aceitação de jovens estudantes cristãos acerca de tópicos que refletem explicações científicas para a origem do homem. O estudo de natureza quantitativa teve a coleta de dados realizada por meio de um questionário numa escala Likert de quatro pontos, aplicado a 1916 estudantes na faixa etária de 15 anos. Os dados apontam que a rejeição dos estudantes em relação à evolução humana como um todo, principalmente pelos estudantes evangélicos, visto que apresentaram níveis mais baixos de concordância com o item, leva a acreditar que, muitas vezes, em sala de aula, a explicação científica sobre a origem do homem contraria a visão de mundo religiosa dos estudantes.

Palavras-chave: Educação em ciências. Ensino de evolução. Evolução biológica. Evolução humana.

\section{Abstract}

The relevance of the teaching of biological evolution is based on the centrality of the theme that is preponderant for the construction of biological knowledge. Despite the centrality, biological evolution is quite controversial as the theme in science classes, causing many teachers to avoid teaching it. Faced with the difficulties inherent in the teaching and learning process of evolutionary theory, especially human evolution, the present work seeks to identify the degree of acceptance of young Christian students on topics that reflect scientific explanations for the origin of man. The quantitative study was carried out using a questionnaire on a 4-point Likert scale, applied to 1916 students in the 15-year age group. The data indicate that the rejection of students in relation to human evolution as a whole, especially by evangelical students, since they presented lower levels of agreement with the item, leads to believe that, often in the classroom, the scientific explanation about the origin of man contradicts the religious worldview of the students.

Keywords: Biological evolution. Evolution teaching. Human evolution. Science education.

Recebido em 03/11/2017 - Aprovado em 22/02/2018

http://dx.doi.org/10.5335/rep.v25i2.8175

Doutora em Educação pela Universidade de São Paulo. Pós-doutoranda no Programa de Pós-Graduação em Ensino de Ciências e Matemática da Universidade Federal de Sergipe. E-mail: helenrios@gmail.com

** Doutor em Educação pela Universidade de São Paulo. Professor titular do Departamento de Metodologia do Ensino da Faculdade de Educação da Universidade de São Paulo (FE/USP). E-mail: nelio.bizzo@gmail.com

*** Doutora em Biotecnologia pela Universidade Federal de Sergipe. Professora adjunta da mesma instituição. E-mail: ylmaia@yahoo.com.br 


\section{Introdução}

Douglas Futuyma define a evolução biológica, numa perspectiva de longo prazo, como "descendência, com modificações, de diferentes linhagens a partir de ancestrais comuns" (2002, p. 9). A fim de que as transformações tornem-se verdadeiramente evolutivas, elas necessitam serem transmitidas hereditariamente entre os indivíduos de uma geração para outra.

Apreender o mundo natural no contexto da evolução é essencial para se compreender os padrões biológicos e a complexidade encontrados na natureza. De acordo com Scott (2010), a biologia, vista à luz da evolução, talvez seja, intelectualmente, a ciência mais inspiradora. Contudo, sem o viés evolucionista, pode tornar-se um amontoado de fatos diversos, alguns deles interessantes ou curiosos, mas sem uma imagem significativa como um todo.

Compreender os conceitos da biologia evolutiva é de grande contribuição para a sociedade. Os fenômenos como por que surgem superbactérias, como ocorre o controle biológico de pragas e insetos, como as vacinas previnem doenças são exemplos de questões sociais que dependem do entendimento de como os processos evolutivos ocorrem.

A relevância do ensino da evolução biológica nas salas de aula de ciências no Brasil é endossada tanto por parte da comunidade científica quanto pelos documentos oficiais curriculares brasileiros, que preconizam a centralidade do tema como preponderante para a construção dos conhecimentos biológicos.

Um exemplo são as Orientações Curriculares para o Ensino Médio (Ocem) que ressaltam a importância do caráter central e integrador do tema. Segundo as Ocem, os conceitos evolutivos não devem estar presentes em apenas um conjunto de conteúdos trabalhados em algumas aulas, mas compor uma linha norteadora das discussões de todos os outros temas:

Esse tema deve ser enfocado dentro de outros conteúdos, como a diversidade biológica ou o estudo sobre a identidade e a classificação dos seres vivos, por exemplo. A presença do tema origem e evolução da vida ao longo de diferentes conteúdos não representa a diluição do tema evolução, mas sim a sua articulação com outros assuntos, como elemento central e unificador no estudo da Biologia (BRASIL, 2006, p. 22, grifo do autor).

Apesar desse caráter fulcral, a evolução biológica é bastante controversa como temática nas aulas de ciências, fazendo com que muitos professores se esquivem de ensiná-la. O seu conteúdo na educação científica envolve uma afluência de fatores sociais, religiosos, políticos e científicos. Estudos (BARBOUR, 2004; MELLO, 2008; STAUB; MEGLHIORATTI, 2011; SILVA, 2011; MOTA, 2013) evidenciam que muitas são as dificuldades encontradas para a abordagem do assunto no contexto do ensino de biologia, tais como: o desconhecimento do princípio unificador da evolução; compreensões inadequadas acerca da natureza da ciência; informações distorcidas sobre a evolução biológica veiculada pelas mídias e por outras institui- 
ções sociais; a falta de compreensão dos conceitos evolutivos; o choque com crenças e valores pessoais dos estudantes e professores. Esses são obstáculos que conferem dificuldades na aprendizagem dos conceitos evolutivos.

Entre as querelas que circundam o ensino de evolução, têm destaque as divergências produzidas no enfrentamento entre as concepções religiosas dos estudantes e a visão científica sobre evolução biológica explanadas em sala de aula pelos professores. Muitas pesquisas (CARNIATTO; ARAGÃO, 1999; SEPÚLVEDA, 2003; SEPÚLVEDA; EL-HANI, 2004; COIMBRA; SILVA, 2007; MELLO, 2008; OLIVEIRA, 2009; PAGAN, 2009) giram em torno de analisar se as crenças religiosas dos estudantes e/ou dos professores influenciam no ensino e na aprendizagem da evolução biológica. Em geral, a religião e os discursos criacionistas foram apontados como itens que parecem influenciar o processo de ensino-aprendizagem, a compreensão e a aceitação da teoria da evolução biológica.

Essa posição central no debate acerca das relações entre educação científica e religiosa pode ser atribuída, por ser o tema que claramente se sobrepõe a visão de mundo religiosa (SEPÚLVEDA; EL-HANI, 2004).

Dentre os tópicos da teoria evolutiva, os princípios sobre a origem e a evolução humana aparentam ser o de menor aceitação por estudantes, professores e público em geral, por abolir explicações divinas para a origem das espécies (OLIVEIRA, 2009; MOTA, 2013).

$\mathrm{O}$ viés religioso de muitos dos enfrentamentos produzidos no ensino de evolução aponta a importância de se investigar as crenças religiosas e suas possíveis influências na compreensão da evolução, no sentido de contribuir para a descrição e a compreensão das relações entre crenças pessoais e percepções das ciências, em geral e particularmente, da teoria da evolução biológica.

Para Cobern (2007), o ensino da evolução biológica suscita reflexões metafísicas que não podem ser ignoradas pelos professores de ciências. O autor considera que a natureza controversa do tema é um bom ponto de partida para se discutir as distintas explicações existentes sobre 0 assunto.

Para que as diversas visões de mundo possam ser discutidas nas sala de aula de ciências, a pertinência da demarcação de outras formas de conhecimento oriundas de outros contextos sociais deve ser levada em conta.

Hodson (1993) afirma que a cultura retratada nesse espaço é exclusivamente da ciência ocidental moderna, mesmo que algumas orientações curriculares apontem para a necessidade de os estudantes reconhecerem a contribuição que as diferentes perspectivas culturais trouxeram para o desenvolvimento da compreensão da ciência. Para o autor, na maior parte das salas de aula de ciências, essas questões raramente são discutidas.

Diante das dificuldades inerentes ao processo de ensino e aprendizagem da teoria evolutiva, especialmente da evolução humana, o presente trabalho busca 
identificar o grau de aceitação de jovens estudantes cristãos acerca de tópicos que refletem explicações científicas para a origem do homem.

A escolha de estudantes cristãos, especialmente evangélicos, se pauta pela ocorrência de posturas, em diversos contextos socioculturais, com viés fundamentalista e antievolucionista. Muitos dos membros desse agrupamento apresentam iniciativas pedagógicas que fortalecem o criacionismo nas escolas por meio de eventos e publicações, como forma de combater o ensino da teoria da evolução (SCB, 2017).

\section{Metodologia}

A pesquisa foi de natureza quantitativa, descritiva. Este estudo foi realizado no contexto do projeto cooperativo internacional The relevance of science education (Rose) (A relevância do ensino de ciências). O Rose busca identificar fatores afetivos considerados importantes pelos estudantes no aprendizado e no conhecimento de ciência e tecnologia, que tanto podem ser utilizados para fazer com que os alunos se interessem mais pelo tema quanto podem ser considerados como pilares para a discussão sobre estruturação curricular do ensino de ciências.

O projeto vem sendo desenvolvido de forma colaborativa por diversos pesquisadores ao redor do mundo e já foi aplicado em mais de 40 países (SCHREINER; SJØBERG, 2004).

\section{A amostra}

O levantamento amostral que determinou o tamanho da amostra foi realizado de acordo com os métodos estatísticos mais usuais, de modo a conseguir um erro de estimação previamente estabelecido, com grau de confiança de 95\% (BUSSAB; MORETTIN, 2011).

\section{0 instrumento de coleta de dados}

O instrumento de coleta de dados foi validado por meio de diversas pesquisas internacionais em diversos contextos socioculturais. O questionário no Brasil foi traduzido e adaptado pelo pesquisador Tolentino Neto (2008) no seu doutoramento. Com o intuito de possibilitar que o Rose fosse utilizado em comparações internacionais, o instrumento utilizado no Brasil seguiu a mesma formatação de fonte, parágrafo, tamanho, papel e quebra de páginas, mantendo o padrão já aplicado e estruturado em outros países (TOLENTINO NETO, 2008).

Para utilizá-lo no projeto de pesquisa em escala nacional, foram realizadas algumas alterações na linguagem que facilitassem a compreensão dos estudantes. A 
natureza colaborativa do projeto oportuniza que cada país inclua questões regionais ao instrumento, possibilitando análises censitárias e outras de cunho qualitativo.

No Brasil, foram incluídas seções acerca do tema evolução biológica e religião. A relevância do tema, além de ser um dos assuntos mais controversos no ensino de ciências, fomentou a escolha do conteúdo a ser somado ao questionário Rose Brasil.

As seções nacionais do questionário foram elaboradas a fim de estabelecer relações entre a opção religiosa do aluno e o ensino de evolução. A parte do questionário destinada ao tema evolução biológica e religião foi composta de 23 itens, distribuídos em cinco seções, com respostas expressas em uma escala Likert de quatro pontos: opção 1 (Não concordo/Nunca) à 4 (Concordo/Muitas vezes), com dois níveis intermediários.

Vale ressaltar que o questionário foi impresso em folhas ópticas com personalização a laser das folhas de respostas, o que permitiu a captura digital das respostas. Esse sistema possibilita a leitura rápida e precisa dos dados, coletados com muito mais segurança e processados com muito mais eficiência e produtividade. $\mathrm{O}$ Brasil foi o primeiro país participante do projeto a utilizar essa tecnologia.

\section{Os sujeitos da pesquisa}

Os sujeitos da pesquisa foram estudantes que estavam completando os estudos compulsórios e iniciando a última etapa da educação básica, momento em que tomam decisões sobre seu futuro profissional.

Por convenção, todos os países participantes selecionaram o nível escolar em que se esperaria encontrar idealmente os estudantes com 15 anos de idade. No caso brasileiro, essa norma foi seguida optando-se pela aplicação do questionário a jovens do primeiro ano do ensino médio.

A coleta de dados foi realizada durante o período de julho de 2010 a setembro de 2011. Os questionários foram enviados para as escolas acompanhados de uma carta de orientação, do termo de consentimento livre e esclarecido, conforme as instruções do comitê de ética da instituição de pesquisa responsável pelo projeto Rose no Brasil, e de envelopes selados para o retorno dos questionários preenchidos.

Ao término da coleta de dados, retornaram envelopes de 84 escolas, totalizando 2.365 questionários preenchidos, número que, de acordo com os critérios estatísticos usuais, é considerado satisfatório para a amostragem proposta inicialmente, já que tem margem de erro entre 3 e 4 pontos percentuais, a mesma do plano amostral inicial.

Os dados coletados foram tabulados por planilha eletrônica e armazenados em um banco de dados para análise. Foram realizadas análises exploratórias e descritivas (estatísticas descritivas) que permitiram conhecer as características da distribuição de dados. Os resultados foram apresentados por análise exploratória 
e descritivo-comparativa entre gêneros, por meio de tabelas de frequência, porcentual, médias, desvio padrão e outros, a fim de apresentar as características da amostra e identificar o grau de aceitação ou rejeição dos alunos sobre os assuntos abordados. As análises foram realizadas utilizando o pacote estatístico Statistical Package for Social Science (SPSS), versão 15.0, o programa R, o programa Microsoft Office Excel e o Knime. Neste trabalho, as distribuições foram organizadas e representadas principalmente pelas frequências relativas.

No presente estudo, só apresentamos os dados referentes à origem do ser humano e à sua evolução, a partir de explicações naturais e das atitudes de aceitação de estudantes cristãos da amostra, que selecionaram como opção religiosa a religião católica ou o "agregado evangélico", no qual se somam os protestantes históricos (de imigração e de missão), os pentecostais e, também, os chamados neopentecostais (ROCHA; ZORZIN, 2012). Essa é a mesma composição dos grupos de religião evangélica utilizada no Censo Demográfico de 2010 realizado pelo Instituto Brasileiro de Geografia e Estatística (IBGE). Sendo assim, são analisados apenas os dados de 1.916 estudantes: 1.237 católicos e 679 evangélicos.

\section{Resultados e discussão}

\section{Opção religiosa dos estudantes}

Em relação às opções religiosas dos estudantes, $64,56 \%$ se declararam católicos, e 35,44\%, evangélicos (Tabela 1).

Tabela 1 - Opção religiosa dos estudantes

\begin{tabular}{l|c|c}
\multicolumn{1}{c|}{ Qual é a sua religião? } & Número de respostas & Porcentagem (\%) \\
\hline Católica & 1.237 & 64,56 \\
\hline Evangélica & 679 & 35,44 \\
\hline Total & $\mathbf{1 . 9 1 6}$ & $\mathbf{1 0 0 , 0 0}$ \\
\hline
\end{tabular}

Fonte: elaboração dos autores.

A religião predominante entre os estudantes é a católica, o que já era esperado, visto que o Brasil é considerado o país com o maior número de católicos no mundo.

Entre as denominações religiosas evangélicas mapeadas, foram encontrados adeptos do protestantismo de imigração (luteranos), do protestantismo de missão (presbiterianos) e batistas pentecostais e neopentecostais (Batista Ágape, Batista Bíblica Metodista Wesleiana $)^{1}$ - Congregacional Cristã Assembleia de Deus, Quadrangular, Maranata, Servindo a Cristo, Filadélfia para Nações, Palavra Viva, 
Igreja de Cristo, Caminho da Verdade, Voz do Evangelho, Cristã do Brasil, Evangélica de Deus, Renovada em Cristo, Igreja Videira, Voz do Evangelho, Igreja Universal do Reino de Deus, Sara Nossa Terra, Igreja Internacional da Graça de Deus.

\section{Origem do ser humano e sua evolução a partir de explicações naturais}

Os tópicos referentes à origem do ser humano e à sua evolução, a partir de explicações naturais, estão dispostos nas questões EH1 ("Os primeiros seres humanos viveram no ambiente africano"), EH2 (“A espécie humana habita a Terra há cerca de 100 mil anos") e EH3 ("O ser humano se originou da mesma forma como as demais espécies biológicas”).

Tendo em vista a possibilidade de a atitude dos jovens estudantes diferirem de acordo com sua opção religiosa, foram estabelecidas associações dos resultados de cada questão desta seção com a variável opção religiosa.

Em relação aos primeiros humanos terem vivido no ambiente africano (Figura 1), os resultados revelaram que os estudantes cristãos evangélicos (60,67\%) apresentaram atitude de rejeição em relação a essa afirmação. Os estudantes cristãos católicos apresentaram 53,56\% de discordância.

Figura 1 - Dados do item EH1

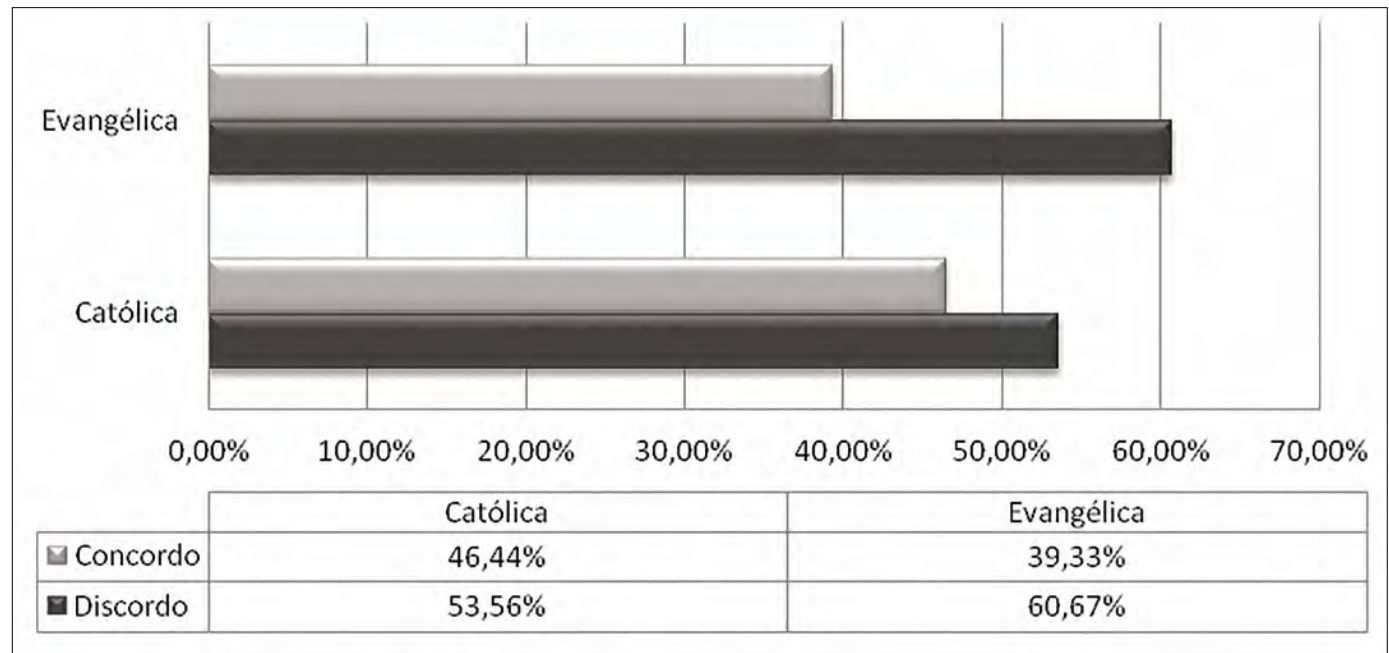

Fonte: elaboração dos autores.

O resultado reflete uma deficiência ou, até mesmo, uma ausência de abordagem científica contextualizada sobre a evolução biológica do homem nas aulas de ciências e biologia. A construção do conhecimento sobre as origens do homem e 
da evolução vem sendo conduzida por meio de estudos que apontam que os seres humanos provavelmente originaram-se no continente africano.

Para Wedderburn (2005), faz-se necessário o permanente estudo da história do continente africano relacionado com a evolução humana, pois esta é uma questão complexa que fomenta controvérsias de natureza social, cultural e étnica, até mesmo de cunho racista.

Ao aferir as opiniões dos jovens cristãos a respeito de a espécie humana habitar a Terra há cerca de 100 mil anos (Figura 2), observa-se que os estudantes cristãos católicos foram os que apresentaram maior aceitação. Os estudantes cristãos evangélicos representaram $52,92 \%$ de discordância ao item.

Figura 2 - Dados do item EH2

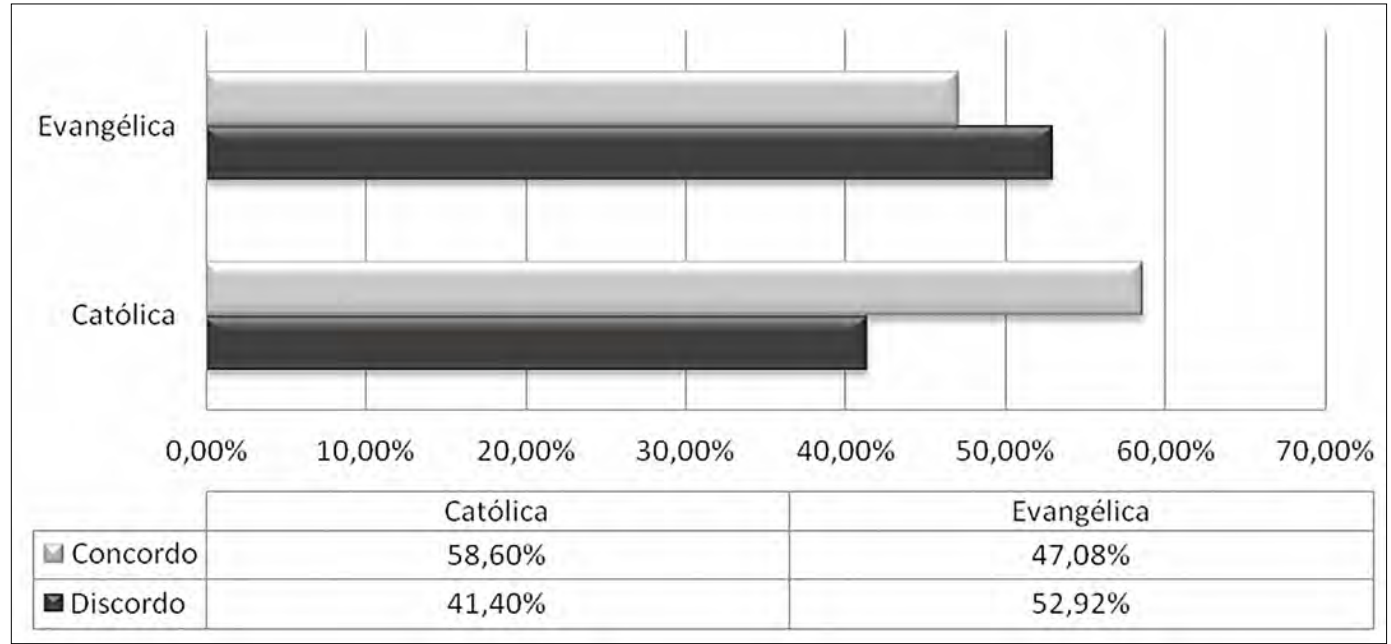

Fonte: elaboração dos autores.

Essa é uma questão que geralmente apresenta rejeição por parte de religiosos que seguem literalmente o relato bíblico de que Deus criou o mundo e os seres vivos cerca de 10 mil anos atrás.

Esses índices também demonstram a importância da compreensão de tempo geológico por parte de estudantes e professores de biologia, ao longo do processo de construção do pensamento evolutivo. Uma boa percepção da extensa dimensão do tempo geológico por meio das escalas geológicas poderia auxiliar o entendimento do surgimento recente da espécie humana ao longo da história da Terra.

Esses resultados corroboram uma carência da compreensão da perspectiva do tempo geológico por parte dos jovens estudantes brasileiros. A magnitude da escala de tempo geológico, utilizada na evolução biológica para representar um elo entre a geologia e a biologia evolutiva, é difícil de ser compreendida pelos estudantes. 
Bizzo e Oliveira (2011) relatam que, ao longo do percurso da moderna geologia italiana, foram realizados, na virada do século XVIII, grandes debates sobre o entendimento das grandes revoluções pelas quais passou a superfície da Terra e sobre a literalidade dos relatos bíblicos do Gênesis, especialmente o dilúvio bíblico, em relação à idade da Terra. Os debates foram acompanhados pelo professor italiano Giambatista Brocchi (1772-1826), que atualmente é considerado precursor da perspectiva da evolução biológica. Os estudos de Brocchi sobre malacologia fóssil dos Apeninos, de 1814, conhecidos como a Analogia de Brocchi, apresentaram uma ideia consistente de extinção: os indivíduos têm um nascimento, uma maturidade e um decaimento até o desaparecimento completo, com a morte; o mesmo ocorreria com as espécies, até sua extinção final.

Em um trabalho mais recente, Bizzo e Oliveira (2012) chamam a atenção para o fato de que, ao contrário de Darwin, Brocchi não defendia um tempo geológico muito extenso; ainda assim, contribuiu para a formulação de um tempo geológico bastante extenso, base necessária para as teorias modernas da evolução.

Em relação ao ser humano ter se originado da mesma forma como as demais espécies biológicas (Figura 3), os estudantes católicos tiveram um percentual de concordância de $53,50 \%$. Já os estudantes evangélicos apresentaram discordância de $58,24 \%$, o que demonstra que rejeitam a ideia de a origem do ser humano ter ocorrido da mesma maneira que as demais espécies biológicas, preferindo a explicação da criação divina.

Figura 3 - Dados do item EH3

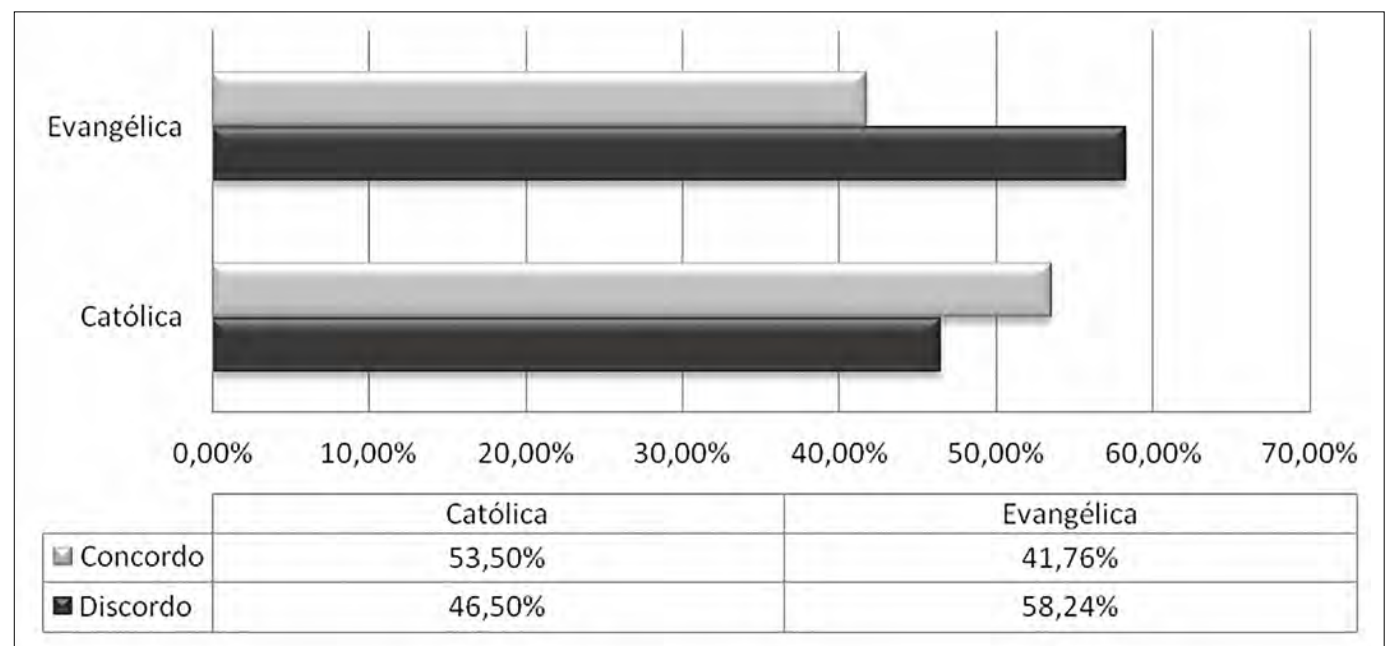

Fonte: elaboração dos autores. 
De acordo Sepúlveda e El-Hani (2001), nas questões que versam sobre a origem do universo, da evolução da vida, existe uma superposição entre ciência e religião, em que se torna inevitável a geração de conflitos, cujo grau vai depender de diversos fatores, entre eles, a natureza da interpretação da doutrina religiosa, que pode ser liberal ou fundamentalista.

Os autores recomendam o uso de casos históricos de cientistas com crenças religiosas como alternativa para a abordagem de possíveis conflitos, vivenciados por alguns estudantes, sobre as explicações científicas e seus dogmas religiosos, o que contribui também para uma melhor compreensão da natureza da ciência.

\section{Considerações finais}

Os estudantes cristãos evangélicos apresentaram um maior grau de discordância nos tópicos referentes à origem do ser humano e à sua evolução a partir de explicações naturais, em relação aos estudantes católicos.

Ao propor a origem do homem da mesma forma que a das demais espécies biológicas, foi difícil a aceitação de que o surgimento de novas características no homem tenha acontecido por conta dos mesmos processos que regem a evolução biológica dos seres vivos.

A rejeição dos estudantes em relação à evolução humana como um todo, principalmente pelos estudantes evangélicos, visto que apresentaram níveis mais baixos de concordância com os itens, leva a acreditar que, muitas vezes, em sala de aula, a explicação científica sobre a origem do homem contraria a visão de mundo religiosa dos estudantes.

Nesse sentido, Oliveira e Bizzo (2011) apontam que o grau de conexão que os estudantes estabelecem com os dogmas religiosos influencia nas diferentes posturas relacionadas aos conhecimentos científicos, e essas relações levam a crer que os contextos social e cultural podem interferir nas escolhas dos conhecimentos científicos que são por eles aceitos.

No entanto, Cobern et al. (2011) fazem o alerta de que se deve ter cautela ao analisar as visões de oposição sobre a evolução de estudantes e professores cristãos, pois análises simplistas podem alimentar o antievolucionismo na educação científica. Segundo os autores, a comunidade científica deve investigar como estudantes e professores cristãos ortodoxos integram os conhecimentos evolutivos e religiosos, os processos de raciocínio e as bases de conhecimento que alicerçam as discordâncias dos tópicos de evolução biológica.

A utilização de acontecimentos históricos controversos, no âmbito da relação entre ciência e religião, envolvendo cientistas no decorrer da história científica, é 
sugerida por Cobern (1991), com o propósito de mostrar aos estudantes que muitos cientistas, que também eram religiosos, desenvolveram uma visão de mundo compatível com a ciência.

Dessa forma, uma abordagem histórico-filosófica da história da evolução humana pode ser um instrumento de relevância no processo de ensino e aprendizagem da biologia evolutiva.

\section{Nota}

1 Apesar das denominações, batistas e metodistas não se encontram no grupo do protestantismo histórico ou de missão, por se declararem pentecostais.

\section{Referências}

BARBOUR, I. G. Quando a ciência encontra a religião. São Paulo: Cultrix, 2004.

BIZZO, N. M. V.; OLIVEIRA, J. B. Tempo Geológico nas perspectivas histórica, epistemológica e sociocultural: resultados de uma pesquisa transnacional In: ENCONTRO NACIONAL DE PESQUISA EM EDUCAÇÃO EM CIÊNCIAS, 8, 2011, Campinas. Anais... Campinas: Enpec, 2011. p. 1-14.

Giambattista Brocchi (1772-1826) e as paleoheteromorfias na alvorada do século XIX. Filosofia e História da Biologia, São Paulo, v. 7, n. 2, p. 281-303, 2012.

BRASIL. Ministério da Educação. Orientações curriculares para o ensino médio: linguagens, códigos e suas tecnologias. Brasília, DF: Secretaria de Educação Básica, 2006.

BUSSAB,W. O.; MORETTIN, P. A. Estatística básica. 7. ed. São Paulo: Saraiva, 2011.

CARNIATTO, I.; ARAGÃO, R. M. R. Investigação narrativa - a questão epistemológica no ensino de conteúdos conceituais, representacionais e processuais da Ciências/Biologia. In: ENCONTRO NACIONAL DE PESQUISA EM EDUCAÇÃO EM CIÊNCIAS, 2, Valinhos, SP. Atas... Valinhos: Abrapec, 1999. p. 1-12.

COBERN, W. W. World View Theory and Science Education Research. Manhattan-Kansas: Narst, 1991.

The competing influence of secularism and religion on science education in a secular society. In: WORKSHOP ON SCIENCE EDUCATION AND SECULAR VALUES, Hartford, 2007. Disponível em: <http://www.wmich.edu/slcsp/SLCSP174/ SLCSP174.pdf>. Acesso em: 4 set. 2017.

COBERN, W. W. et al. Thinking about science and christian orthodox beliefs: a survey study of teacher beliefs. 2011. (Seminário apresentado no Mallinson Institute for Science Education em 11 de abril de 2011). Disponível em: <https://files.eric.ed.gov/fulltext/ED518279.pdf>. Acesso em: 15 ago. 2017. 
COIMBRA, R. L.; SILVA, J. Ensino de evolução biológica e a necessidade de formação continuada. In: ENCONTRO NACIONAL DE PESQUISA EM EDUCAÇÃO EM CIÊNCIAS, 6, Florianópolis, 2007. Atas... Florianópolis: Abrapec, 2007. p. 1-14.

FUTUYMA, D. J. Evolução, ciência e sociedade. São Paulo: Sociedade Brasileira de Genética, 2002.

HODSON, D. In search of a rationale for multicultural science education. Science Education, Flórida, v. 77, p. 685-711, 1993.

MELLO, A. C. Evolução biológica: concepções de alunos e reflexões didáticas. 2008. 114 f. Dissertação (Mestrado em Educação em Ciências e Matemática) - Faculdade de Física, Pontifícia Universidade Católica do Rio Grande do Sul, Porto Alegre, 2008.

MOTA, H. S. Evolução biológica e religião: atitudes de jovens estudantes brasileiros. 2013. 275 f. Tese (Doutorado em Educação) - Faculdade de Educação, Universidade de São Paulo, São Paulo, 2013.

OLIVEIRA, G. S. Aceitação/rejeição da evolução biológica: atitudes de alunos da educação básica. 2009. 162 f. Dissertação (Mestrado em Educação) - Faculdade de Educação, Universidade de São Paulo, São Paulo, 2009.

OLIVEIRA, G. S.; BIZZO, N. M. V. Aceitação da evolução biológica: atitudes de estudantes do ensino médio de duas regiões brasileiras. Revista Brasileira de Pesquisa em Educação em Ciências, Rio de Janeiro, v. 11, n. 1, p. 57-79, 2011.

PAGAN, A. A. Ser (animal) humano: evolucionismo e criacionismo nas concepções de alguns graduandos em Ciências Biológicas. 2009. 228 f. Tese (Doutorado em Educação) - Faculdade de Educação, Universidade de São Paulo, São Paulo, 2009.

ROCHA, D.; ZORZIN, P. Os evangélicos em números: algumas observações sobre o que revelou (e o que não revelou) o estudo Novo Mapa das Religiões sobre o agregado evangélico brasileiro. In: SIMPÓSIO DA ABHR, 13. Anais... Goiânia: ABHR, 2012. p. 1-15.

SCHREINER, C.; SJØBERG, S. Sowing the seeds of Rose. Background, rationale, questionnaire development and data collection for Rose (the relevance of science education) - a comparative study of students' views of science and science education. Acta Didactica (4/2004): dept. of teacher education and school development. University of Oslo: Norway, 2004.

SEPÚLVEDA, C. A relação entre religião e Ciência na trajetória profissional de alunos protestantes da Licenciatura em Ciências Biológicas. 2003. 307 f. Dissertação (Mestrado em Ensino, Filosofia e História das Ciências) - Universidade Federal da Bahia e Universidade Estadual de Feira de Santana, Salvador, 2003.

SEPÚLVEDA, C.; EL-HANI, C. N. Analisando as relações entre educação científica e educação religiosa: II. O uso de casos históricos de cientistas com crenças religiosas como ferramenta na formação de professores. In: ENCONTRO NACIONAL DE PESQUISA EM EDUCAÇÃO EM CIÊNCIAS, 3, Atibaia. Atas... Atibaia: Abrapec, 2001. p. 1-12.

Quando visões de mundo se encontram: religião e ciência na trajetória de formação de alunos protestantes de uma licenciatura em ciências biológicas. Investigações em Ensino de Ciências, Porto Alegre, v. 9, n. 2, p. 1-49, 2004. 
SCB. Sociedade Criacionista Brasileira. 2017. Disponível em: <http://www.scb.org.br/>. Acesso em: 10 jun. 2017.

SCOTT, E. C. Cans and Can'ts of Teaching Evolution. 2010. Disponivel em: <https://ncse.com/ library-resource/cans-cants-teaching-evolution>. Acesso em: 14 set. 2017.

SILVA, E. William Buck Bagby: um pioneiro batista nas terras do Cruzeiro do Sul. Rio de Janeiro: Novos diálogos, 2011.

STAUB, T.; MEGLHIORATTI, A. Análise da controvérsia entre evolução biológica e crenças pessoais em docentes de um curso de ciências biológicas. In: ENCONTRO INTERNACIONAL DE PRODUÇÃO CIENTIFICA, 7, Maringá. Anais... Maringá: Cesumar, 2011.

TOLENTINO NETO, L. C. B. de. Os interesses e posturas de jovens alunos frente às ciências: resultados do projeto Rose aplicado no Brasil. 2008. 172 f. Tese (Doutorado em Educação) - Faculdade de Educação, Universidade de São Paulo, São Paulo, 2008.

WEDDERBURN, C. M. Novas bases para o ensino da história da África no Brasil. In: EDUCAÇÃO anti-racista: caminhos abertos pela Lei Federal 10.639/00. Brasília: MEC-Secad, 2005. p. 134-142. Disponível em: <http://unesdoc.unesco.org/images/0014/001432/143283por.pdf>. Acesso em: 25 abr. 2018. 